\title{
Hypertension and coronary artery ectasia: a systematic review and meta-analysis study
}

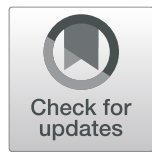

\author{
Mostafa Bahremand ${ }^{1}$, Ehsan Zereshki ${ }^{2^{*}}$ (D), Behzad Karami Matin² ${ }^{2}$, Mansour Rezaei ${ }^{2}$ (D) and Hamidreza Omrani ${ }^{3}$ (D)
}

\begin{abstract}
Background: Coronary artery ectasia (CAE) is characterized by the enlargement of a coronary artery to 1.5 times or more than other non-ectasia parts of the vessel. It is important to investigate the association of different factors and CAE because there are controversial results between available studies. We perform this systematic review and metaanalysis to evaluate the effects of hypertension (HTN) on CAE.

Methods: To find the potentially relevant records, the electronic databases, including Scopus, PubMed, and Science Direct were searched on 25 July 2019 by two of the authors independently. In the present study, the pooled odds ratio (OR) accompanied by $95 \%$ confidence intervals (Cls) were calculated by a random-effects model.

Heterogeneity presented with the $\mathrm{I}^{2}$ index. Subgroup analysis and sensitivity analysis by the Jackknife approach was performed.

Results: Forty studies with 3,263 cases and 7,784 controls that investigated the association between HTN and CAE were included. The pooled unadjusted OR of CAE in subjects with HTN in comparison by subjects without HTN was estimated 1.44 ( $95 \% \mathrm{Cl}, 1.24$ to 1.68$)$ with moderate heterogeneity $\left(I^{2}=41 \%\right.$, Cochran's $\left.Q P=0.004\right)$. There was no evidence of publication bias in the analysis of HTN and CAE with Egger's test $(P=0.171)$, Begg's test $(P=0.179)$. Nine articles reported the adjusted effect of HTN on CAE by 624 cases and 628 controls. The findings indicated the overall adjusted OR was $1.03(95 \% \mathrm{Cl}, 0.80$ to 1.25$)$ with high heterogeneity $\left(I^{2}=58.5 \%\right.$, Cochran's $\mathrm{Q} P=0.013$ ).

Conclusions: We found that when the vessel was in normal condition, HTN was not very effective in increasing the chance of CAE and only increased the CAE chance by $3 \%$. This is an important issue and a warning to people who have multiple risk factors together. More studies need to be performed to further establish these associations by reported adjusted effects.
\end{abstract}

Keywords: Hypertension, Coronary artery disease, Meta-analysis, Systematic review

\section{Background}

Coronary artery ectasia (CAE) is characterized by the enlargement of a coronary artery to 1.5 times or more than other non-ectasia parts of the vessel [1]. CAE is defined by increasing the pressure of the wall vessel, the thin arterial wall which causes advanced dilation and reforming of the vessel [2]. The fixed dilation of the artery is to be usually caused by inflammation, disease,

\footnotetext{
* Correspondence: ehsan.zereshki@kums.ac.ir

${ }^{2}$ Research Center for Environmental Determinants of Health (RCEDH), Health Institute, Kermanshah University of Medical Sciences, Kermanshah, Iran Full list of author information is available at the end of the article
}

chemicals, or physical stress of the vessel [2]. It makes the heart tissue to be deprived of blood and die because of decreased blood flow and blockages due to blood clots or spasms of the blood vessel [3]. CAE is commonly asymptomatic and is normally discovered when performing tests for other conditions such as coronary artery disease, stable angina, and other acute coronary syndromes. It is estimated that the incidence of CAE was to be in the range of $1-5 \%$ in angiographic examinations [4]. Some studies had indicated the risk factors such as; hyperlipidemia, obesity, diabetes mellitus (DM), and other factors that could be significantly associated with a

(c) The Author(s). 2021 Open Access This article is licensed under a Creative Commons Attribution 4.0 International License, which permits use, sharing, adaptation, distribution and reproduction in any medium or format, as long as you give appropriate credit to the original author(s) and the source, provide a link to the Creative Commons licence, and indicate if changes were made. The images or other third party material in this article are included in the article's Creative Commons licence, unless indicated otherwise in a credit line to the material. If material is not included in the article's Creative Commons licence and your intended use is not permitted by statutory regulation or exceeds the permitted use, you will need to obtain permission directly from the copyright holder. To view a copy of this licence, visit http://creativecommons.org/licenses/by/4.0/ The Creative Commons Public Domain Dedication waiver (http://creativecommons.org/publicdomain/zero/1.0/) applies to the data made available in this article, unless otherwise stated in a credit line to the data. 
higher risk of CAE [5-11]. The relationship between CAE and hypertension (HTN) is not clear in the view of pathophysiology, or cause and result but it is commonly found in patients with diseases of atherosclerosis, connective tissue, and an increased inflammatory response [12, 13]. Also one of the clinical reasons for CAE might be the pressure effect on the artery wall in the blood flow. It results in the artery dilate by pushing blood on the artery wall. This performance is called common shear stress [2, 14] and it would be increased by HTN [15]. Also, HTN has been suggested as a risk factor for CAE [10, 16-19]. HTN is a global problem, especially in developing countries [20]. Approximately, $16.5 \%$ of deaths annually (9.5 million deaths) are attributed to HTN [21]. HTN is defined as systolic blood pressure (SBP) $\geq 140 \mathrm{mmHg}$ and/ or diastolic blood pressure (DBP) $\geq 90 \mathrm{mmHg}$ according to the World Health Organization.

Although the association of HTN and CAE has been widely studied, information regarding the relationship between this factor and the CAE is limited. Many studies have not reported the adjusted effect of HTN on CAE [22-26]. It is important to investigate the adjusted effect of HTN on CAE because there are controversial results between available studies. A study reported $114 \%$ more chance of CAE for subjects with HTN than the control group [27]. Another study showed $142 \%$ more chance of CAE in the HTN group [28]. In contrast, a study expressed ineffective HTN on CAE [29] or the other study showed the prospective effect of HTN on CAE [30]. To the best of our knowledge, there is no metaanalysis study to show this relation.

Based on the literature review, the risk factors related to the CAE were quantitatively analyzed. Therefore, this systematic review and meta-analysis study aimed to clarify and quantify of HTN effect on CAE.

\section{Methods}

\section{Data source and search strategy}

This study was prepared according to the preferred reporting items for systematic reviews and meta-analyses (PRISMA) statement [31]. A comprehensive systematic search was conducted in electronic databases including Scopus, PubMed, and Science Direct without a time limit until July 25, 2019. We used the following keywords and Mesh (Medical Subject Headings) terms to search literature: ("coronary artery ectasia" OR "CAE" OR "coronary heart disease" OR "CAD" OR "coronary artery aneurysm" AND "hypertension" OR "HTN" OR "blood pressure"). We also checked the references of the obtained articles to find more relevant potential publications.

\section{Inclusion and exclusion criteria}

Inclusion criteria were as follows: (1) articles with full text in English, (2) publications considered odds ratio
(OR) with $95 \%$ confidence interval (CI) for CAE between subjects with and without HTN, or (3) reported the number of subjects with and without HTN in CAE and non-CAE groups. Publications were excluded with the following characteristics: (1) duplicates, (2) books, case reports, conference, and editorial articles, (3) absence of HTN, (4) full text not available. The obtained articles were reviewed by two authors (EZ and $\mathrm{MB}$ ) and confirm with the third person (MR).

\section{Data extraction and quality assessment}

Information was collected for each included study: study ID (first author's name), publication year, country that study conducted in, type of study (case-control and cross-sectional), participant characteristics (number of sample size and age), outcomes require characteristics (HTN, DM, family history of coronary artery disease $[\mathrm{CAD}]$, recently smoked, hyperlipidemia, and body mass index $[\mathrm{BMI}])$. Before selecting studies to enter the metaanalysis, we assessed them for risk of bias. We used the Mixed Method Appraisal Tool (MMAT) ("quantitative non-randomized" part of MMAT) to investigate the quality of included studies. MMAT can be used for studies with different structures, including qualitative, quantitative, and mixed with different designs. The reliability and validity of MMAT were confirmed in previous studies [32]. This checklist is designed to have two basic questions that will be further explored if any study is accepted on both questions. The quality of articles is evaluated with five questions in the "quantitative nonrandomized" part of MMAT. The quality of articles is determined by high quality (5), medium quality (4 or 3 ), or low quality ( 1 or 2 ). The summary results of the quality assessment were provided in Table 1.

\section{Statistical analysis}

In the present study, the random-effects model through a generic inverse-variance method was used to calculate the pooled OR and $95 \% \mathrm{CI}$ of CAE in subjects with HTN in comparison to subjects without HTN. The Stata/SE ver. 14 (Stata Corp., College Station, TX, USA) was used for meta-analysis and the following programs were: mean to conduct random-effects meta-analysis to obtain estimates for the relationship of HTN between CAE cases and the control group. Heterogeneity presented with calculated $\mathrm{I}^{2}$ index, and $\mathrm{I}^{2}$ values of $0 \%$, $25 \%, 50 \%$, and $75 \%$ represents no, low, moderate, and high heterogeneity, respectively [53]. We used funnel plots that announce publication bias that the Egger's and begg's tests confirm that by the statistical formula. A Pvalue of less than 0.05 was chosen to test the null hypothesis in all analyses [54, 55]. If heterogeneity exceeds $50 \%$, the Jackknife approach was used. The Jackknife approach examines the effect of each study. This method 
Table 1 Characteristics of included studies

\begin{tabular}{|c|c|c|c|c|c|c|c|c|c|c|c|c|}
\hline Study ID & Year & Country & $\mathrm{CAE}+$ & CAE- & Design & HTN & DM & F.CAD & Hyp & Smoke & BMI & MMAT score \\
\hline Aghajani et al. [33] & 2017 & Iran & 27 & 33 & Case-control & $\checkmark$ & $x$ & $x$ & $x$ & $x$ & $x$ & 4 \\
\hline Akturk et al. [34] & 2018 & Turkey & 40 & 40 & Case-control & $\checkmark$ & $x$ & $x$ & $x$ & $x$ & $x$ & 3 \\
\hline Antonopoulos et al. [35] & 2016 & Greece & 39 & 41 & Case-control & $\checkmark$ & $x$ & $x$ & $x$ & $x$ & $x$ & 2 \\
\hline Baysal et al. [36] & 2018 & Turkey & 32 & 35 & Cross-sectional & $\checkmark$ & $x$ & $x$ & $x$ & $x$ & $x$ & 3 \\
\hline Boles et al. [30] & 2017 & Sweden & 16 & 26 & Cross-sectional & $\checkmark$ & $\checkmark$ & $\checkmark$ & $\checkmark$ & $\checkmark$ & $\checkmark$ & 2 \\
\hline Brunetti et al. [37] & 2014 & Italy & 14 & 15 & Cross-sectional & $\checkmark$ & $x$ & $x$ & $x$ & $x$ & $x$ & 2 \\
\hline Demir et al. [38] & 2013 & Turkey & 126 & 122 & Cross-sectional & $\checkmark$ & $x$ & $x$ & $x$ & $x$ & $x$ & 3 \\
\hline Dogan et al. [39] & 2016 & Turkey & 167 & 150 & Cross-sectional & $\checkmark$ & $x$ & $x$ & $x$ & $x$ & $x$ & 4 \\
\hline Dursun et al. [22] & 2015 & Turkey & 30 & 30 & Cross-sectional & $\checkmark$ & $\checkmark$ & $x$ & $x$ & $x$ & $\checkmark$ & 3 \\
\hline Erdogan et al. [23] & 2013 & Turkey & 49 & 30 & Cross-sectional & $\checkmark$ & $\checkmark$ & $\checkmark$ & $\checkmark$ & $\checkmark$ & $\checkmark$ & 4 \\
\hline Farrag et al. [24] & 2013 & Egypt & 192 & 2,408 & Cross-sectional & $\checkmark$ & $\checkmark$ & $\checkmark$ & $x$ & $\checkmark$ & $x$ & 3 \\
\hline Gok et al. [25] & 2018 & Turkey & 52 & 33 & Case-control & $\checkmark$ & $\checkmark$ & $x$ & $x$ & $\checkmark$ & $x$ & 5 \\
\hline Ipek et al. [26] & 2016 & Turkey & 99 & 1,556 & Case-control & $\checkmark$ & $\checkmark$ & $x$ & $\checkmark$ & $\checkmark$ & $x$ & 4 \\
\hline Isik et al. [40] & 2012 & Turkey & 75 & 96 & Cross-sectional & $\checkmark$ & $\checkmark$ & $\checkmark$ & $x$ & $\checkmark$ & $x$ & 5 \\
\hline Iwanczyk et al. [28] & 2019 & Poland & 27 & 27 & Cross-sectional & $\checkmark$ & $x$ & $x$ & $x$ & $x$ & $x$ & 3 \\
\hline Kalaycioglu et al. [41] & 2014 & Turkey & 138 & 139 & Cross-sectional & $\checkmark$ & $\checkmark$ & $\checkmark$ & $\checkmark$ & $\checkmark$ & $x$ & 5 \\
\hline Karaagac et al. [42] & 2014 & Turkey & 28 & 22 & Case-control & $\checkmark$ & $\checkmark$ & $x$ & $x$ & $\checkmark$ & $x$ & 2 \\
\hline Katritsis et al. [16] & 2010 & France & 27 & 30 & Cross-sectional & $\checkmark$ & $\checkmark$ & $x$ & $x$ & $\checkmark$ & $\checkmark$ & 3 \\
\hline Kiris et al. [17] & 2012 & Turkey & 34 & 24 & Cross-sectional & $\checkmark$ & $\checkmark$ & $\checkmark$ & $x$ & $\checkmark$ & $\checkmark$ & 4 \\
\hline Kiziltunc et al. [43] & 2016 & Turkey & 41 & 72 & Cross-sectional & $\checkmark$ & $\checkmark$ & $x$ & $x$ & $\checkmark$ & $x$ & 3 \\
\hline Kundi et al. [44] & 2017 & Turkey & 52 & 33 & Cross-sectional & $\checkmark$ & $x$ & $x$ & $x$ & $x$ & $x$ & 3 \\
\hline Liang et al. [45] & 2019 & China & 87 & 90 & Cross-sectional & $\checkmark$ & $x$ & $x$ & $x$ & $x$ & $x$ & 4 \\
\hline Liu et al. [46] & 2016 & China & 32 & 31 & Case-control & $\checkmark$ & $\checkmark$ & $\checkmark$ & $x$ & $\checkmark$ & $\checkmark$ & 3 \\
\hline Luo et al. [47] & 2017 & China & 51 & 100 & Case-control & $\checkmark$ & $x$ & $x$ & $x$ & $x$ & $x$ & 5 \\
\hline Ozbek et al. [5] & 2016 & Turkey & 117 & 70 & Cross-sectional & $\checkmark$ & $\checkmark$ & $\checkmark$ & $\checkmark$ & $\checkmark$ & $\checkmark$ & 4 \\
\hline Ozde et al. [6] & 2018 & Turkey & 55 & 55 & Case-control & $\checkmark$ & $\checkmark$ & $\checkmark$ & $x$ & $\checkmark$ & $\checkmark$ & 4 \\
\hline Qin et al. [7] & 2019 & China & 100 & 100 & Cross-sectional & $\checkmark$ & $\checkmark$ & $x$ & $x$ & $\checkmark$ & $\checkmark$ & 3 \\
\hline Quisi et al. [8] & 2018 & Turkey & 51 & 50 & Case-control & $\checkmark$ & $\checkmark$ & $\checkmark$ & $\checkmark$ & $\checkmark$ & $\checkmark$ & 4 \\
\hline Sarli et al. [18] & 2014 & Turkey & 210 & 100 & Case-control & $\checkmark$ & $x$ & $x$ & $x$ & $x$ & $x$ & 5 \\
\hline Satiroglu et al. [48] & 2015 & Turkey & 20 & 28 & Cross-sectional & $\checkmark$ & $\checkmark$ & $\checkmark$ & $x$ & $\checkmark$ & $\checkmark$ & 3 \\
\hline Schram et al. [27] & 2018 & Netherland & 77 & 154 & Case-control & $\checkmark$ & $x$ & $x$ & $x$ & $x$ & $x$ & 2 \\
\hline Sen et al. [19] & 2014 & Turkey & 100 & 80 & Case-control & $\checkmark$ & $\checkmark$ & $\checkmark$ & $x$ & $\checkmark$ & $\checkmark$ & 5 \\
\hline Sen et al. [49] & 2007 & Turkey & 67 & 45 & Cross-sectional & $\checkmark$ & $\checkmark$ & $x$ & $x$ & $\checkmark$ & $\checkmark$ & 3 \\
\hline Tuzun et al. [29] & 2007 & Turkey & 35 & 35 & Cross-sectional & $\checkmark$ & $x$ & $x$ & $x$ & $x$ & $x$ & 3 \\
\hline Uygun et al. [50] & 2019 & Turkey & 41 & 45 & Cross-sectional & $\checkmark$ & $\checkmark$ & $\checkmark$ & $x$ & $\checkmark$ & $\checkmark$ & 5 \\
\hline Varol et al. [51] & 2009 & Turkey & 366 & 160 & Case-control & $\checkmark$ & $x$ & $x$ & $x$ & $x$ & $x$ & 3 \\
\hline Wang et al. [52] & 2017 & China & 72 & 72 & Cross-sectional & $\checkmark$ & $x$ & $x$ & $x$ & $x$ & $x$ & 5 \\
\hline Yalcin et al. [9] & 2015 & Turkey & 40 & 44 & Cross-sectional & $\checkmark$ & $\checkmark$ & $\checkmark$ & $x$ & $\checkmark$ & $\checkmark$ & 4 \\
\hline Yang et al. [10] & 2013 & China & 131 & 1,269 & Cross-sectional & $\checkmark$ & $\checkmark$ & $\checkmark$ & $x$ & $\checkmark$ & $\checkmark$ & 4 \\
\hline Yolcu et al. [11] & 2016 & Turkey & 62 & 57 & Cross-sectional & $\checkmark$ & $\checkmark$ & $\checkmark$ & $\checkmark$ & $\checkmark$ & $x$ & 3 \\
\hline
\end{tabular}

CAE+ participants with coronary artery ectasia (CAE), CAE- participants without CAE; HTN hypertension (reported in study), DM diabetes mellitus (reported in study), F.CAD family history of coronary artery disease (reported in study), Hyp hyperlipidemia (reported in study); Smoke, recent smoked (reported in study), BMI body mass index (reported in study), MMAT Mixed Method Appraisal Tool 
works by reporting the results of all other articles by excluding each study. If the result exceeds the specified CI, it indicates the high effect of that study. This method was used as a sensitivity analysis to estimate the potential publication bias on the overall estimates in the metaanalysis [56]. Also, subgroup analysis will distinct that there are significant differences in the type of study and quality of the study.

\section{Results}

\section{Study selection}

As shown in Fig. 1 and 576 studies were found based on the search strategy, and 10 studies by manually search. After deleting duplicate articles, 500 documents remained, and by examining their titles and abstracts, we reached 76 articles. After reviewing the full text of the remaining articles, 24 articles were discarded due to irrelevant results. Seven articles that were case reports, conferences, or editorials were also removed. Four papers were deleted for non-English text and one study was deleted due to lack of full text. Ultimately 40 articles [5-11, 16-19, 22-30, 33-52] were included in the metaanalysis.

\section{Study characteristics}

The summary characteristics of studies were shown in Table 1, there are 40 studies [5-11, 16-19, 22-30, 3352] include 14 case-control $[6,8,18,19,25-27,33-35$, $42,46,47,51]$ and 26 cross-sectional studies [5, 7, 9-11, $16,17,22-24,28-30,36-41,43-45,48-50,52]$. The studies with 11,047 participants, 3,263 cases, and 7,784 controls were included. All studies have determined the number of subjects with and without HTN in the two groups with and without CAE, which we can calculate the OR of CAE in the two groups. Only nine articles reported the adjusted OR of HTN allocated to CAE. The criteria for HTN were the same in all studies (SBP > 140 and/or DBP > 90). In all studies, men and women were
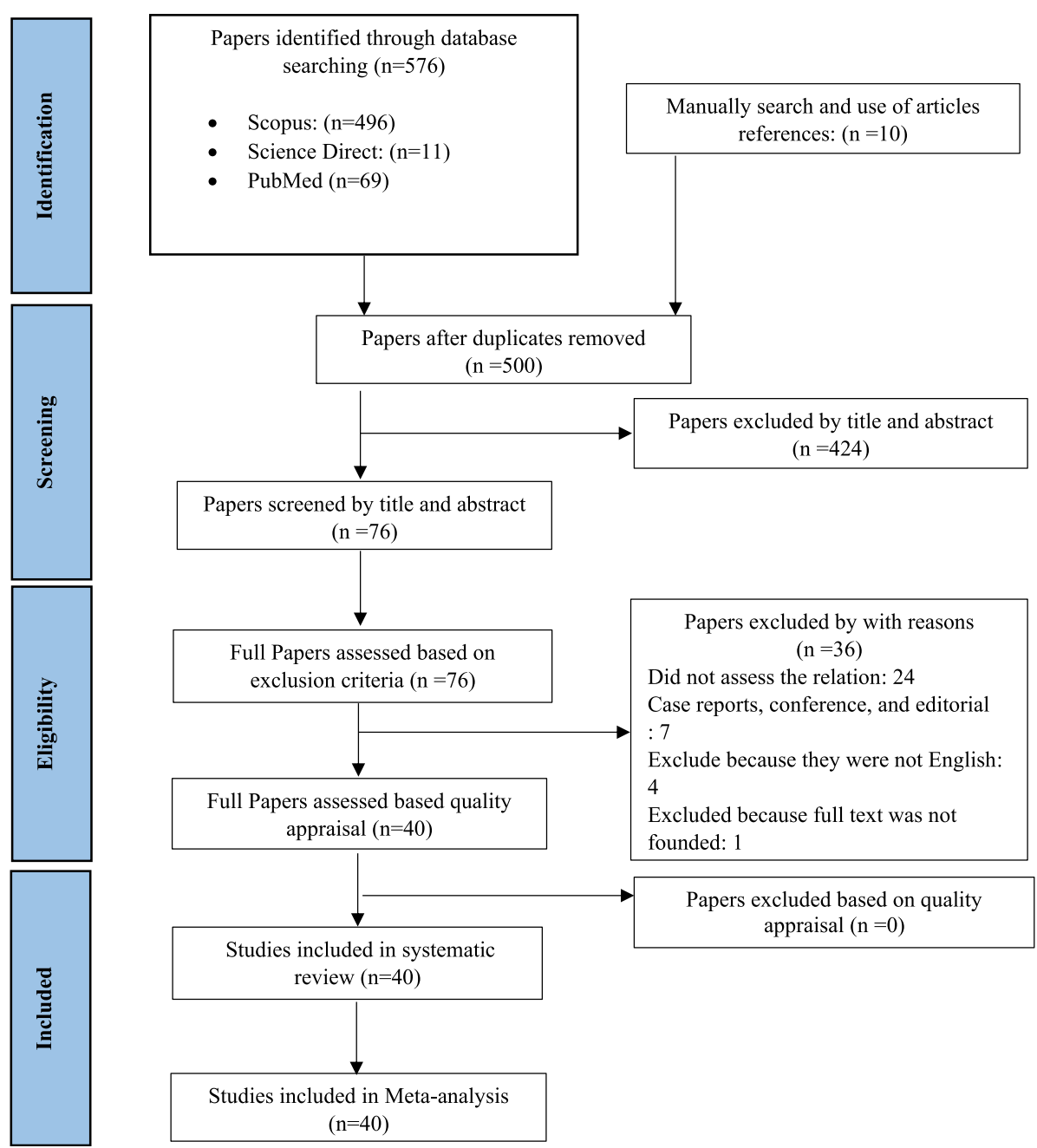

Fig. 1 Inclusion criteria of preferred reporting items for systematic reviews and meta-analyses (PRISMA) flow chart 
examined simultaneously. In all studies, the mean age of participants was 47 to 71 years old in the case group (with CAE) and over 48 to 69 years old in the control group (without CAE). Studies have been done in different countries; there were six studies conducted in China, 28 in Turkey, and one for each of these countries (Egypt, France, Greece, Iran, Italy, Poland, Sweden, and The Netherlands). However, the criterion for assessing the outcome (CAE) is the same in all studies (coronary angiography), except for one study [24] that was performed with different criteria (scanner). The median year of publication of studies was 2016 .

\section{Risk of bias}

The obtained articles were reviewed by two authors and confirm with a third person. As mentioned in Table 1, the results examined for risk of bias for studies based on the MMAT, all studies had an acceptable quality for inclusion in the study and according to the "quantitative non-randomized" part of the checklist, eight studies had a low risk of bias [18, 19, 25, 40, 41, 47, 50, 52], 27 studies had a moderate risk of bias $[5-11,16,17,22-24,26$,
$28,29,33,34,36,38,39,43-46,48,49,51]$, and five studies had a high risk of bias [27, 30, 35, 37, 42].

\section{Statistical analyses}

Forty studies with 3,263 cases and 7,784 controls that investigated the association between $\mathrm{HTN}$ and CAE were included. The pooled unadjusted OR of CAE in subjects with HTN compared to subjects without HTN was estimated 1.44 (95\% CI, 1.24 to 1.68 ) with low heterogeneity $\left(I^{2}=41 \%\right.$; Cochran's $\left.Q P=0.004\right)$ (Fig. 2). There was no evidence of publication bias in the analysis of HTN and CAE with Egger's test $(P=0.171)$, Begg's test $(P=0.179)$, and study effect sizes distributed in a funnel plot (Fig. 3).

\section{Sensitivity and subgroup analyses}

The Jackknife method was used to investigate the effect of each study on the total effect size and heterogeneity. As shown in Fig. 4, none of the studies alone have a significant effect on the overall result of the study and do not distort the overall result, and it cannot be concluded that the heterogeneity that exists is due to the existence

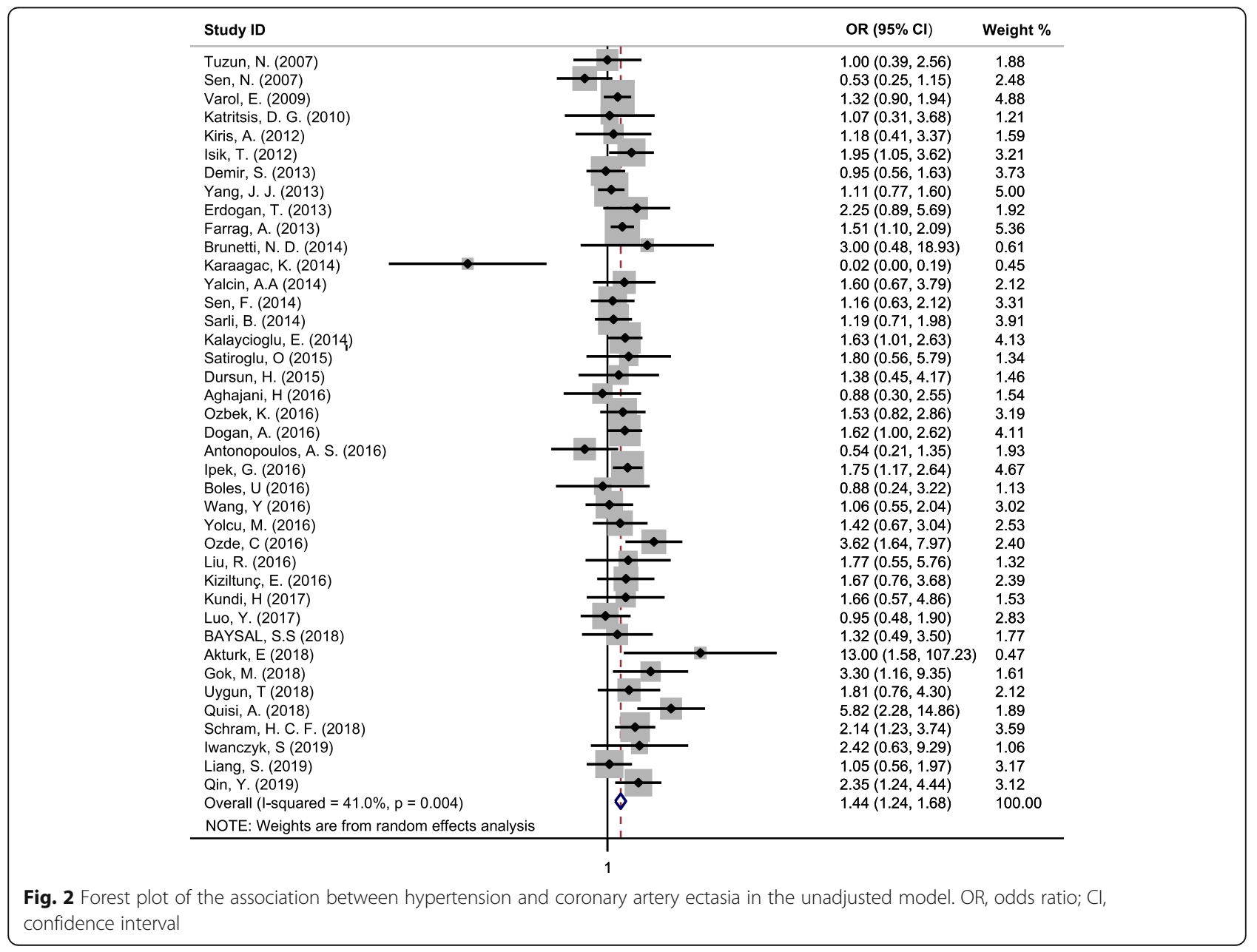




\section{Funnel plot with pseudo $95 \%$ confidence limits}

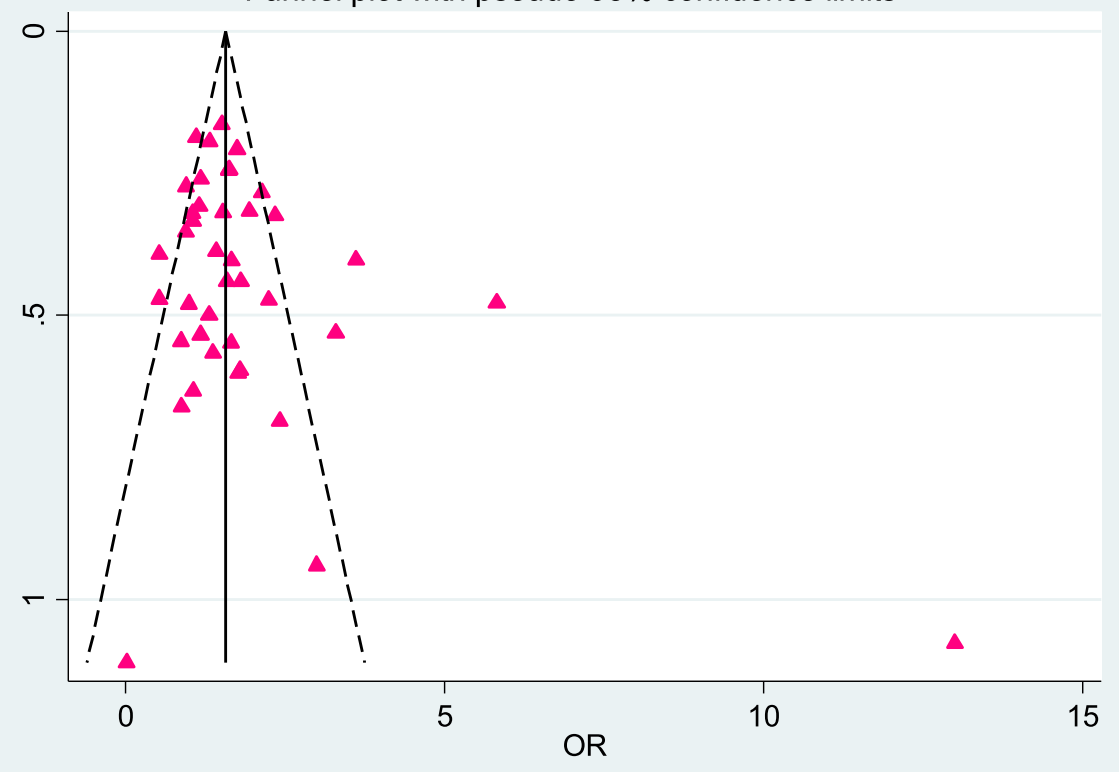

Fig. 3 Funnel plot of hypertension and coronary artery ectasia of publication bias. OR, odds ratio

of a particular study. To further investigate the heterogeneous cause, we used subgroup analysis and examined the outcome for the type of study and quality of the study. For the type of study, results showed that in casecontrol studies, the OR for subjects with HTN compared to subjects without HTN was $1.53(95 \% \mathrm{CI}, 1.06$ to
2.21) with moderate heterogeneity $\left(\mathrm{I}^{2}=71.3 \%\right.$; Cochran's $Q P=0.001$ ). But in cross-sectional studies, the OR for subjects with HTN than subjects without HTN was 1.39 ( $95 \%$ CI, 1.22 to 1.58 ) with no heterogeneity $\left(\mathrm{I}^{2}=0 \%\right.$; Cochran's $\left.\mathrm{Q} P=0.738\right)$ (Fig. S1). For the quality of the study, based on the scoring of the MMAT,

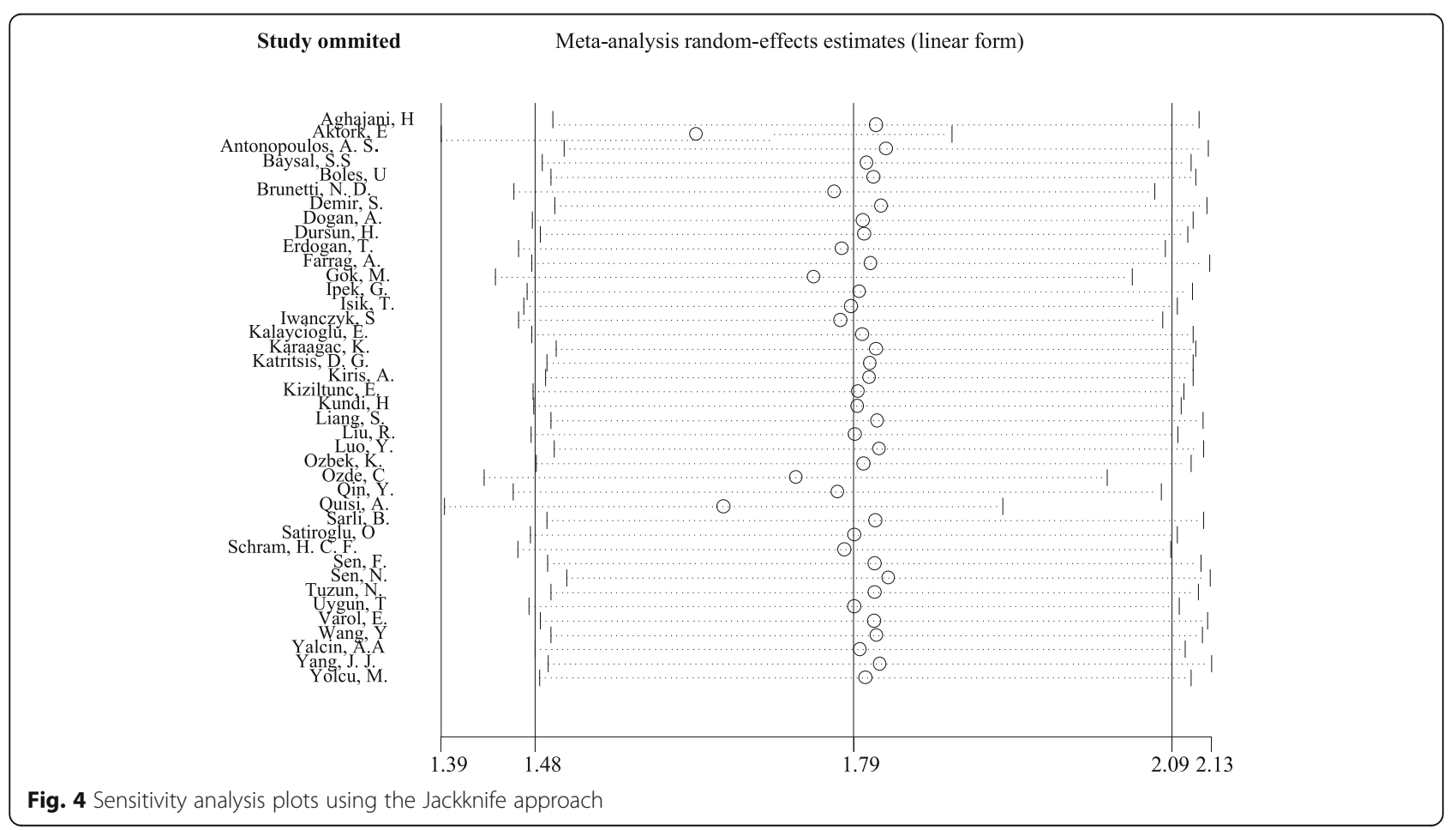


the studies were divided into three categories: high quality, moderate quality, and low quality. In high quality studies, the outcome (OR) was 1.40 (95\% CI, 1.12 to $1.76)$ with no heterogeneity $\left(\mathrm{I}^{2}=1.7 \%\right.$; Cochran's $\mathrm{Q} P=$ 0.417). In moderate quality studies, the outcome was 1.49 (95\% CI, 1.27 to 1.76$)$ with low heterogeneity $\left(\mathrm{I}^{2}=\right.$ $29.7 \%$; Cochran's Q $P=0.075)$, but in low quality studies, the outcome was 0.71 ( $95 \% \mathrm{CI}, 0.21$ to 2.35 ) with high heterogeneity $\left(\mathrm{I}^{2}=81.4 \%\right.$; Cochran's $\left.\mathrm{Q} P=0.001\right)$ (Fig. S2). Additionally, we utilized the meta-regression analysis for the year of publication of the articles. For one year of increasing articles, the possibility of increasing the risk of CAE in people with HTN was reported to be $18 \%$ higher $(95 \% \mathrm{CI}, 1.10$ to 1.30$)$ with high heterogeneity $\left(\mathrm{I}^{2}=85.4 \%\right.$; Cochran's $\left.\mathrm{Q} P<0.001\right)$ (Fig. S3).

\section{Discussion}

The main purpose of this systematic review and metaanalysis study was to evaluate the chances of CAE due to HTN. To find potentially relevant records, electronic databases were searched. Finally, 40 articles were included in the meta-analysis. The risk of CAE in subjects with HTN was $44 \%$ higher than in subjects without HTN. Our result was consistent with a meta-analysis study that evaluated the risk of HTN on a similar disease (abdominal aortic aneurysms) that reported a $66 \%$ higher risk of abdominal aortic aneurysms in high HTN patients [57]. The result of a recent study showed $135 \%$ more chance of CAE in HTN subjects than the no-HTN group [7]. Also, a study reported $66 \%$ more chance of CAE in HTN subjects than the control group [44] that confirms the effect of HTN on CAE.

One of the clinical reasons for CAE might be the pressure effect on the artery wall in the blood flow. This is because HTN is caused by two parts, the systole, and the diastole. By pumping blood through the arteries from the heart (systole) and returning blood from the arteries to the heart (diastole), it results in the artery dilate by pushing blood on the artery wall. This performance is called common shear stress $[2,14]$. But we are looking for the adjusted effect of HTN on CAE. Because HTN is caused by unhealthy lifestyles, it needed to clarify whether this effect on CAE is directly related to HTN or not.

Variety factors could confuse the HTN effect on CAE, for instance, BMI is an important factor that affected several diseases. A person with a BMI above 25 usually has high blood lipids (hyperlipidemia) $[58,59]$. This disease is usually chronic and requires ongoing medication to control blood lipid levels [2]. Blood lipids over time cause fat to build up in the arteries and it makes the arteries narrow. Narrowing in one part of the artery can put too much pressure on the artery and dilate the area around it $[60,61]$. This confirmed by our results, it was a $35 \%$ higher chance of CAE in hyperlipidemia cases than in the control group (Fig. S4).

DM is the factor that has a potential effect on coroners. In DM, the destruction of beta-cell occurs in the pancreas [62]. The main cause of the loss of $\beta$ cells is cellular damage caused by the cellular immune response [63]. Following this destruction, markers are released into the bloodstream, causing damage to the vein [64]. This is in line with the results we achieved. We found that DM increased a $19 \%$ chance of CAE than the control group (Fig. S5).

Smoking is one of the main causes of cardiovascular disease $[65,66]$. By smoking, carbon monoxide and other toxic substances enter the bloodstream, which reduces blood oxygenation and less oxygen to the heart, which increases heart pumping and increases blood pressure that leads to a contraction in the arteries, this condition is a risk factor for CAE [67-70]. Our analysis found that those who had recently smoked were in a $53 \%$ more chance of developing the CAE than the control group (Fig. S6).

Some diseases can be influenced by genetic or familial factors. Cardiovascular disease is one of these diseases that family history can increase the risk of that [71-73]. In our research, we found that there was a $22 \%$ higher chance of CAE in family history of CAD cases than in the control group (Fig. S7).

The presence of different variables along with HTN can confound the results of the study. For investigating the adjusted effect of HTN on CAE, we survey adjusted reports of HTN. In the 40 articles reviewed, nine articles reported the adjusted effect of HTN on CAE by 624 cases and 628 controls [5, 7, 8, 25, 26, 34, 40, 41, 47]. The findings indicated the overall adjusted OR was 1.03 $(95 \% \mathrm{CI}, 0.80$ to 1.25$)$ with moderate heterogeneity $\left(\mathrm{I}^{2}=58.5 \%\right.$; Cochran's Q $P=0.013$ ) (Fig. 5). This states a $41 \%$ lower effect of unadjusted effect $(\mathrm{OR}=1.44)$, which indicates the interaction rule of other factors.

\section{Limitations}

It's should be noted that this study was accompanied by several limitations both in study and outcome levels. The included studies had case-control and crosssectional designs that are associated with inherent limitations to investigate a cause-effect relationship, for this limitation we performed subgroup analysis. Case-control studies show a stronger effect between HTN and CAE, but as you can see, there is higher heterogeneity in these studies (Fig. S1). This is because CAE is a chronic disease and the effect of variables on this disease is timeconsuming.

Besides, the studies were carried out in different countries and it can be discussed whether the results of these studies can be combined. A review of the studies 


\begin{tabular}{lll} 
Study ID & OR (95\% Cl) & Weight \% \\
Isik (2012) & $2.88(1.14,7.31)$ & 0.52 \\
Kalaycioglu (2014) & $1.28(0.78,2.09)$ & 8.64 \\
Ipek (2016) & $1.71(1.14,2.58)$ & 7.49 \\
Ozbek (2016) & $2.58(0.97,6.69)$ & 0.60 \\
Luo (2017) & $0.77(0.42,1.42)$ & 12.47 \\
Gok (2018) & $1.16(0.99,1.33)$ & 27.37 \\
Akturk (2018) & $0.22(0.05,1.09)$ & 11.78 \\
Quisi (2018) & $7.92(1.56,40.14)$ & 0.01 \\
Qin (2019) & $1.03(0.99,1.16)$ & 31.10 \\
Overall (I-squared = 58.5\%, $\mathrm{p}=0.013)$ & $1.03(0.80,1.25)$ & 100.00 \\
NOTE: Weights are from random effects analysis & & \\
\hline
\end{tabular}

Fig. 5 Forest plot of the association between hypertension and coronary artery ectasia in the adjusted model. OR, odds ratio; $\mathrm{Cl}$, confidence interval

revealed that all studies except one of them used a measurement criterion to diagnose the disease. Based on MMAT, articles had different qualities. To investigate this issue, we used the subgroup analysis. Eight studies a had high quality that OR for CAE in HTN subjects than NonHTN subjects was 1.40 (95\% CI, 1.12 to 1.76$)$ with no heterogeneity ( $\mathrm{I}^{2}=1.7 \%$; Cochran's $\left.\mathrm{Q} P=0.417\right), 27$ studies had a moderate quality that OR was 1.49 (95\% CI, 1.27 to 1.76 ) with low heterogeneity $\left(\mathrm{I}^{2}=29.7 \%\right.$; Cochran's $\mathrm{Q} P=$ 0.075 ) and five studies had a low quality that OR between two groups was 0.71 (95\% CI, 0.21 to 2.35 ) with high heterogeneity $\left(\mathrm{I}^{2}=81.4 \%\right.$; Cochran's $\left.\mathrm{Q} P=0.001\right)$ (Fig. S2). After eliminating the low-quality studies, the results were as follows. OR between the two groups was 1.46 (95\% CI, 1.28 to 1.67$)$ with low heterogeneity $\left(\mathrm{I}^{2}=23.0 \%\right.$; Cochran's Q $P=0.113$ ) (Fig. S8). It was better to examine this outcome for the sex variable, but none of the studies examined the effect of HTN on CAE for the sex variable. Also, the number of participants in the two groups of subjects (with HTN and without HTN), was not reported separately and we could not calculate the OR for sex effect on CAE. It is suggested that this outcome for the sex variable be investigated in future studies.

\section{Conclusions}

We found that when the vessel was in normal condition, HTN was not very effective in increasing the chance of CAE. When a person had other risk factors which caused the vessels to be abnormal, the HTN increased the chance of CAE $44 \%$, while the adjusted HTN effect only increased the CAE chance by $3 \%$. More longitudinal studies are needed to more accurately investigate the effect of HTN on CAE by considering the limitations mentioned.

\section{Abbreviations}

BMI: Body mass index; CAD: Coronary artery disease; CAE: Coronary artery ectasia; Cl: Confidence interval; DBP: Diastolic blood pressure; DM: Diabetes mellitus; HTN: Hypertension; MMAT: Mixed Method Appraisal Tool; OR: Odds ratio; PRISMA: Preferred Reporting Items for Systematic Reviews and MetaAnalyses; SBP: Systolic blood pressure

\section{Supplementary Information}

The online version contains supplementary material available at https://doi. org/10.1186/s40885-021-00170-6.

Additional file 1: Figure S1. Forest plot of the association between type of study and coronary artery ectasia.

Additional file 2: Figure S2. Forest plot of the association between quality of study and coronary artery ectasia.

Additional file 3: Figure S3. Bubble plot for the effect of year on the coronary artery ectasia by meta-regression analysis.

Additional file 4: Figure S4. Forest plot of the association between hyperlipidemia and coronary artery ectasia.

Additional file 5: Figure S5. Forest plot of the association between diabetes mellitus and coronary artery ectasia.

Additional file 6: Figure S6. Forest plot of the association between recently smoked and coronary artery ectasia.

Additional file 7: Figure S7. Forest plot of the association between family history of heart disease and coronary artery ectasia.

Additional file 8: Figure S8. Forest plot of the association between high and moderate studies and coronary artery ectasia.

\section{Acknowledgements}

Not applicable.

\section{Authors' contributions}

$\mathrm{MB}$ and $\mathrm{EZ}$ contributed to the overall conception and design of the work. EZ and MR contributed to the acquisition, analysis, and interpretation of data for the work. EZ, BKM, HO, and MB drafted the manuscript. All authors critically revised the manuscript and gave final approval. All agree to be accountable for all aspects of work ensuring integrity and accuracy. 


\section{Funding}

This study was supported by Research Deputy of Kermanshah University of Medical Sciences (Grant number: 980986). They had no role in study design, data collection and analysis, preparation of the manuscript or decision to publish.

\section{Availability of data and materials}

All data that support the conclusions of this manuscript are included within the article [5-11, 16-19, 22-30, 33-52].

\section{Declarations}

Ethics approval and consent to participate

Not applicable.

\section{Consent for publication}

Not applicable.

\section{Competing interests}

The authors declare that they have no competing interests.

\section{Author details}

${ }^{1}$ Cardiovascular Research Center, Health Institute, Kermanshah University of Medical Sciences, Kermanshah, Iran. ${ }^{2}$ Research Center for Environmental Determinants of Health (RCEDH), Health Institute, Kermanshah University of Medical Sciences, Kermanshah, Iran. ${ }^{3}$ Imam Reza Hospital Research Center, Kermanshah University of Medical Sciences, Kermanshah, Iran.

Received: 27 December 2020 Accepted: 2 June 2021

Published online: 15 July 2021

\section{References}

1. Lin CT, Chen CW, Lin TK, Lin CL. Coronary artery ectasia. Tzu Chi Med J. 2008;20:270-4

2. Hsu PC, Su HM, Lee HC, Juo SH, Lin TH, Voon WC, et al. Coronary collateral circulation in patients of coronary ectasia with significant coronary artery disease. PLoS One. 2014;9:e87001.

3. Antoniadis AP, Chatzizisis YS, Giannoglou GD. Pathogenetic mechanisms of coronary ectasia. Int J Cardiol. 2008;130:335-43.

4. Sultana R, Sultana N, Ishaq M, Samad A. The prevalence and clinical profile of angiographic coronary ectasia. J Pak Med Assoc. 2011;61:372-5.

5. Ozbek K, Katlandur H, Keser A, Ulucan S, Ozdil H, Ulgen MS. Is there a relationship between mean platelet volume and the severity of coronary ectasia? Biomed Res. 2016;27:816-20.

6. Ozde C, Korkmaz A, Kundi H, Oflar E, Ungan I, Xankisi V, et al. Relationship between plasma levels of soluble CD40 ligand and the presence and severity of isolated coronary artery ectasia. Clin Appl Thromb Hemost. 2018; 24:379-86.

7. Qin Y, Tang C, Ma C, Yan G. Risk factors for coronary artery ectasia and the relationship between hyperlipidemia and coronary artery ectasia. Coron Artery Dis. 2019;30:211-5.

8. Quisi A, Alici G, Allahverdiyev S, Genc O, Baykan AO, Ozbicer S, et al. Impaired oscillometric arterial stiffness parameters in patients with coronary artery ectasia. Turk Kardiyol Dern Ars. 2018;46:366-74.

9. Yalcin AA, Topuz M, Akturk IF, Celik O, Erturk M, Uzun F, et al. Is there a correlation between coronary artery ectasia and neutrophil-lymphocyte ratio? Clin Appl Thromb Hemost. 2015;21:229-34.

10. Yang JJ, Yang X, Chen ZY, Wang Q, He B, Du LS, et al. Prevalence of coronary artery ectasia in older adults and the relationship with epicardial fat volume by cardiac computed tomography angiography. J Geriatr Cardiol. 2013;10:10-5.

11. Yolcu M, Ipek E, Turkmen S, Ozen Y, Yildirim E, Sertcelik A, et al. The relationship between elevated magnesium levels and coronary artery ectasia. Cardiovasc J Afr. 2016;27:294-8.

12. Tilson MD. Aortic aneurysms and atherosclerosis. Circulation. 1992;85:378-9.

13. Thompson RW. Basic science of abdominal aortic aneurysms: emerging therapeutic strategies for an unresolved clinical problem. Curr Opin Cardiol. 1996;11:504-18.

14. Malek AM, Alper SL, Izumo S. Hemodynamic shear stress and its role in atherosclerosis. JAMA. 1999;282:2035-42.
15. Singh PK, Marzo A, Howard B, Rufenacht DA, Bijlenga P, Frangi AF, et al. Effects of smoking and hypertension on wall shear stress and oscillatory shear index at the site of intracranial aneurysm formation. Clin Neurol Neurosurg. 2010;112:306-13

16. Katritsis DG, Zografos T, Korovesis S, Giazitzoglou E, Youinou P, Skopouli FN, et al. Antiendothelial cell antibodies in patients with coronary artery ectasia. Coron Artery Dis. 2010;21:352-6.

17. Kiris A, Bostan M, Korkmaz L, Agac MT, Acar Z, Kaplan S, et al. Carotidfemoral pulse wave velocity in patients with isolated coronary artery ectasia: an observational study. Anadolu Kardiyol Derg. 2012;12:313-9.

18. Sarli B, Baktir AO, Saglam H, Arinc H, Kurtul S, Sivgin S, et al. Neutrophil-tolymphocyte ratio is associated with severity of coronary artery ectasia. Angiology. 2014;65:147-51.

19. Sen F, Yilmaz S, Kuyumcu MS, Ozeke O, Balci MM, Aydogdu S. The presence of fragmented QRS on 12-lead electrocardiography in patients with coronary artery ectasia. Korean Circ J. 2014;44:307-11.

20. Kearney PM, Whelton M, Reynolds K, Muntner P, Whelton PK, He J. Global burden of hypertension: analysis of worldwide data. Lancet. 2005;365:217-23.

21. Lim SS, Vos T, Flaxman AD, Danaei G, Shibuya K, Adair-Rohani H, et al. A comparative risk assessment of burden of disease and injury attributable to 67 risk factors and risk factor clusters in 21 regions, 1990-2010: a systematic analysis for the Global Burden of Disease Study 2010. Lancet. 2012;380: 2224-60.

22. Dursun H, Onrat E, Ozkececi G, Akci O, Avsar A, Melek M. Endothelial dysfunction in patients with isolated coronary artery ectasia: Decreased flow-mediated dilatation in the brachial artery. Biomed Res. 2015;26:328-32.

23. Erdogan T, Kocaman SA, Cetin M, DurakoGlugil ME, Kirbas A, Canga A, et al. Increased YKL-40 levels in patients with isolated coronary artery ectasia: an observational study. Anadolu Kardiyol Derg. 2013;13:465-70.

24. Farrag A, Faramawy AE, Salem MA, Wahab RA, Ghareeb S. Coronary artery ectasia diagnosed using multidetector computed tomography: morphology and relation to coronary artery calcification. Int J Cardiovasc Imaging. 2013; 29:427-33.

25. Gok M, Kundi H, Kiziltunc E, Topcuoglu C, Ornek E. The relationship between serum endocan levels and the presence/severity of isolated coronary artery ectasia. Cardiovasc Endocrinol Metab. 2018;7:42-6.

26. Ipek G, Gungor B, Karatas MB, Onuk T, Keskin M, Tanik O, et al. Risk factors and outcomes in patients with ectatic infarct-related artery who underwent primary percutaneous coronary intervention after ST elevated myocardial infarction. Catheter Cardiovasc Interv. 2016;88:748-53.

27. Schram HC, Hemradj W, Hermanides RS, Kedhi E, Ottervanger JP, Zwolle Myocardial Infarction Study Group. Coronary artery ectasia, an independent predictor of no-reflow after primary PCI for ST-elevation myocardial infarction. Int J Cardiol. 2018;265:12-7.

28. Iwanczyk S, Borger M, Kaminski M, Chmara E, Cieslewicz A, Tykarski A, et al. Inflammatory response in patients with coronary artery ectasia and coronary artery disease. Kardiol Pol. 2019;77:713-5.

29. Tuzun N, Tanriverdi H, Evrengul H, Kuru DS, Ergene AO. Aortic elastic properties in patients with coronary artery ectasia. Circ J. 2007;71:506-10.

30. Boles U, Pinto RC, David S, Abdullah AS, Henein MY. Dysregulated fatty acid metabolism in coronary ectasia: an extended lipidomic analysis. Int J Cardiol. 2017:228:303-8.

31. Moher D, Liberati A, Tetzlaff J, Altman DG, PRISMA Group. Preferred reporting items for systematic reviews and meta-analyses: the PRISMA statement. Ann Intern Med. 2009;151:264-9.

32. Hong QN, Pluye $P$, Fabregues S, Bartlett G, Boardman F, Cargo M, et al. Mixed methods appraisal tool (MMAT) version 2018: user guide. McGill University, Montreal (QC). 2018. http://mixedmethodsappraisaltoolpublic. pbworks.com/w/file/fetch/127916259/MMAT_2018_criteria-manual_2018-0801_ENG.pdf. 2018.

33. Aghajani H, Faal M, Hosseinsabet A, Mohseni-Badalabadi R. Evaluation of left atrial function via two-dimensional speckle-tracking echocardiography in patients with coronary artery ectasia. J Clin Ultrasound. 2017:45:231-7.

34. Aktürk E, Aşkın L, Nacar H, Taşolar MH, Türkmen S, Çetin M, et al. Association of serum prolidase activity in patients with isolated coronary artery ectasia. Anatol J Cardiol. 2018;19:110-6.

35. Antonopoulos AS, Siasos G, Oikonomou E, Mourouzis K, Mavroudeas SE Papageorgiou $\mathrm{N}$, et al. Characterization of vascular phenotype in patients with coronary artery ectasia: the role of endothelial dysfunction. Int J Cardiol. 2016;215:138-9. 
36. Baysal SS, Koç Ş, Güneş A, Altiparmak IH. Endothelium biomarkers endocan and thrombomodulin levels in isolated coronary artery ectasia. Eur Rev Med Pharmacol Sci. 2018;22:4677-82.

37. Brunetti ND, Salvemini G, Cuculo A, Ruggiero A, De Gennaro L, Gaglione A, et al. Coronary artery ectasia is related to coronary slow flow and inflammatory activation. Atherosclerosis. 2014;233:636-40.

38. Demir S, Avsar MK, Karakaya Z, Selcuk M, Tosu AN, Abal G, et al. Increased mean platelet volume is associated with coronary artery ectasia. Postepy Kardiol Interwencyjnej. 2013;9:241-5.

39. Dogan A, Arslan A, Yucel H, Aksoy F, Icli A, Ozaydin M, et al. Gamma glutamyltransferase, inflammation and cardiovascular risk factors in isolated coronary artery ectasia. Rev Port Cardiol. 2016;35:33-9.

40. Isik T, Kurt M, Ayhan E, Uyarel H, Tanboga IH, Korkmaz AF, et al. Relation of red cell distribution width with presence and severity of coronary artery ectasia. Clin Appl Thromb Hemost. 2012:18:441-7.

41. Kalaycıoglu E, Gokdeniz T, Aykan AC, Gül I, Boyacı F, Gursoy OM, et al. Comparison of neutrophil to lymphocyte ratio in patients with coronary artery ectasia versus patients with obstructive coronary artery disease. Kardiol Pol. 2014;72:372-80

42. Karaagac K, Yontar OC, Tenekecioglu E, Vatansever F, Ozluk OA, Tutuncu A, et al. Evaluation of Tp-Te interval and Tp-Te/QTc ratio in patients with coronary artery ectasia. Int J Clin Exp Med. 2014;7:2865-70.

43. Kiziltunc E, Gok M, Kundi H, Cetin M, Topcuoglu C, Gulkan B, et al. Plasma thiols and thiol-disulfide homeostasis in patients with isolated coronary artery ectasia. Atherosclerosis. 2016;253:209-13.

44. Kundi H, Gok M, Topcuoglu C, Ornek E. Association of serglycin levels with isolated coronary artery ectasia. Kardiol Pol. 2017;75:990-6.

45. Liang S, Zhang Y, Gao X, Zhao H, Di B, Sheng Q, et al. Is coronary artery ectasia a thrombotic disease? Angiology. 2019;70:62-8.

46. Liu R, Wu W, Chen L, Chen H, Zhang S. Transcriptional expression profiles of the main proteinases and their regulators in coronary artery ectasia patients' mononuclear cells. Acta Cardiol. 2016;71:157-63.

47. Luo Y, Tang J, Liu X, Qiu J, Ye Z, Lai Y, et al. Coronary artery aneurysm differs from coronary artery ectasia: angiographic characteristics and cardiovascular risk factor analysis in patients referred for coronary angiography. Angiology. 2017;68:823-30.

48. Satiroglu O, Uydu HA, Durakoglugil ME, Demir A, Karadag Z, Bostan M. The relationships of isolated coronary artery ectasia with Urotensin 2 levels, hypertension and other atherosclerotic risk factors. Acta Medica Mediterranea. 2015;31:149-53.

49. Sen N, Tavil Y, Yazici HU, Hizal F, Acikgoz SK, Abaci A, et al. Mean platelet volume in patients with coronary artery ectasia. Med Sci Monit. 2007;13: CR356-9.

50. Uygun T, Demir B, Tosun V, Ungan I, Kural A, Ciftci R, et al. Relationship between interleukin-17A and isolated coronary ectasia. Cytokine. 2019; 115:84-8.

51. Varol E, Akcay S, Ozaydin M, Erdogan D, Dogan A. Mean platelet volume in patients with coronary artery ectasia. Blood Coagul Fibrinolysis. 2009;20:321-4.

52. Wang Y, Zhang Y, Zhu CG, Guo YL, Huang QJ, Wu NQ, et al. Big endothelin1 level is a useful marker for predicting the presence of isolated coronary artery ectasia. Biomarkers. 2017;22:331-6.

53. Higgins JP, Thompson SG. Quantifying heterogeneity in a meta-analysis. Stat Med. 2002;21:1539-58.

54. Peters JL, Sutton AJ, Jones DR, Abrams KR, Rushton L. Contour-enhanced meta-analysis funnel plots help distinguish publication bias from other causes of asymmetry. J Clin Epidemiol. 2008;61:991-6.

55. Begg CB, Mazumdar M. Operating characteristics of a rank correlation test for publication bias. Biometrics. 1994;50:1088-101.

56. Miller RG. The jackknife: a review. Biometrika. 1974;61:1-15.

57. Kobeissi E, Hibino M, Pan H, Aune D. Blood pressure, hypertension and the risk of abdominal aortic aneurysms: a systematic review and meta-analysis of cohort studies. Eur J Epidemiol. 2019;34:547-55.

58. Kawada T. Body mass index is a good predictor of hypertension and hyperlipidemia in a rural Japanese population. Int J Obes Relat Metab Disord. 2002;26:725-9.

59. Charlton M. Obesity, hyperlipidemia, and metabolic syndrome. Liver Transpl. 2009;15(Suppl 2):83-9.

60. Roumeguere T, Wespes E, Carpentier Y, Hoffmann P, Schulman CC. Erectile dysfunction is associated with a high prevalence of hyperlipidemia and coronary heart disease risk. Eur Urol. 2003;44:355-9.
61. Hongo M, Tsutsui H, Mawatari E, Hidaka H, Kumazaki S, Yazaki Y, et al. Fluvastatin improves arterial stiffness in patients with coronary artery disease and hyperlipidemia: a 5-year follow-up study. Circ J. 2008;72:722-8.

62. Like AA, Rossini AA. Streptozotocin-induced pancreatic insulitis: new model of diabetes mellitus. Science. 1976;193:415-7.

63. Dotta F, Censini S, van Halteren AG, Marselli L, Masini M, Dionisi S, et al. Coxsackie B4 virus infection of beta cells and natural killer cell insulitis in recent-onset type 1 diabetic patients. Proc Natl Acad Sci U S A. 2007;104: 5115-20.

64. Papanas N, Symeonidis G, Maltezos E, Mavridis G, Karavageli E, Vosnakidis T, et al. Mean platelet volume in patients with type 2 diabetes mellitus. Platelets. 2004;15:475-8.

65. Ambrose JA, Barua RS. The pathophysiology of cigarette smoking and cardiovascular disease: an update. J Am Coll Cardiol. 2004;43:1731-7.

66. Kannel W, McGee D, Castelli W. Latest perspectives on cigarette smoking and cardiovascular disease: the Framingham Study. J Card Rehabil. 1984;4: 267-77.

67. Kayame R, Mallongi A. Relationships between smoking habits and the hypertension occurrence among the adults of communities in Paniai Regency, Papua Indonesia. Indian J Public Health Res Dev. 2018;9:332-6.

68. Kobayashi F, Watanabe T, Akamatsu Y, Furui H, Tomita T, Ohashi R, et al. Acute effects of cigarette smoking on the heart rate variability of taxi drivers during work. Scand J Work Environ Health. 2005;31:360-6.

69. Manzano BM, Vanderlei LC, Ramos EM, Ramos D. Acute effects of smoking on autonomic modulation: analysis by Poincaré plot. Arq Bras Cardiol. 2011; 96:154-60.

70. Karakaya O, Barutcu I, Kaya D, Esen AM, Saglam M, Melek M, et al. Acute effect of cigarette smoking on heart rate variability. Angiology. 2007:58:620-4.

71. North KE, Howard BV, Welty TK, Best LG, Lee ET, Yeh JL, et al. Genetic and environmental contributions to cardiovascular disease risk in American Indians: the strong heart family study. Am J Epidemiol. 2003;157:303-14.

72. Jones AW, Yao Z, Vicencio JM, Karkucinska-Wieckowska A, Szabadkai G. PGC1 family coactivators and cell fate: roles in cancer, neurodegeneration, cardiovascular disease and retrograde mitochondria-nucleus signalling. Mitochondrion. 2012:12:86-99.

73. McCusker ME, Yoon PW, Gwinn M, Malarcher AM, Neff L, Khoury MJ. Family history of heart disease and cardiovascular disease risk-reducing behaviors. Genet Med. 2004:6:153-8.

\section{Publisher's Note}

Springer Nature remains neutral with regard to jurisdictional claims in published maps and institutional affiliations.

Ready to submit your research? Choose BMC and benefit from:

- fast, convenient online submission

- thorough peer review by experienced researchers in your field

- rapid publication on acceptance

- support for research data, including large and complex data types

- gold Open Access which fosters wider collaboration and increased citations

- maximum visibility for your research: over $100 \mathrm{M}$ website views per year

At $\mathrm{BMC}$, research is always in progress.

Learn more biomedcentral.com/submissions 